\title{
UMA ESCOLA PARA APRENDIZES ARTÍFICES E O ENSINO PROFISSIONAL PRIMÁRIO GRATUITO
}

\section{O. M. MEDEIROS NETA ${ }^{1}$, J. M. NASCIMENTO e A. G. F. RODRIGUES}

${ }^{1}$ Núcleo de Pesquisa em Educação - Instituto Federal de Educação, Ciência e Tecnologia

Campus Central - Natal - RN

E-mail: diac.cnat@ifrn.edu.br

Artigo submetido em maio/2012 e aceito em maio/2012

\section{RESUMO}

Em 23 de setembro de 1909, pelo Decreto no 7566, o Presidente da República dos Estados Unidos do Brasil, Nilo Peçanha, criou nas capitais dos Estados da República Escolas de Aprendizes Artífices para o ensino profissional primário gratuito. Assim, objetivamos refletir sobre a Escola de Aprendizes Artífices de Natal (EAA) no contexto de implantação de dessa rede de Ensino Profissional no Brasil. Para tanto, atentaremos a cultura escolar da EAA e suas práticas cotidianas, seus saberes a ensinar e condutas a inculcar. Nas primeiras décadas do século $X X$, a EAA de Natal manteve um currículo e um conjunto de práticas voltadas à formação do profissional autônomo como o sapateiro, o marceneiro e o curtidor.

PALAVRAS-CHAVE: Ensino profissional, Escola de Aprendizes Artífices, Natal.

\section{A SCHOOL FOR STUDENTS AND EDUCATION PROFESSIONAL PRIMARY CRAFTERS FREE}

\section{ABSTRACT}

On September 23, 1909, under the Decree no. 7566, the President of the Republic of the United States of Brazil, Nilo Peçanha, created, in the capitals of the States of the Republic, the so-called Schools of Apprentice Crafters (SAC) for free elementary professional education. In this way, we aim at reflecting about the School of Apprentice Crafters in Natal/RN in the context of the implementation of this network of Professional
Education in Brazil. To do so, we focus on the school culture of the SAC and its daily practices, knowledge to teach and behaviors to learn. In the first decade of the twentieth century, the SAC in Natal/RN kept a curriculum and a set of practices targeted at the professional who worked for himself such as the shoemaker, the carpenter and the tanner.

KEY-WORDS: Professional education, Schools of Apprentice Crafters, Natal. 


\section{UMA ESCOLA PARA APRENDIZES ARTÍFICES E O ENSINO PROFISSIONAL PRIMÁRIO GRATUITO}

\section{APROXIMAÇÕES E (DE)MARCAÇÕES DE UMA ESCOLA DE APRENDISES ARTÍFICES}

O objetivo deste artigo é refletir sobre a Escola de Aprendizes Artífices de Natal (EAA) no contexto de implantação de uma rede de Ensino Profissional no Brasil, no início do século XX. Dessa forma, atentaremos a cultura escolar da EAA e suas práticas cotidianas, seus saberes a ensinar e condutas a inculcar. (JULIA, 2001).

As Escolas de Aprendizes Artífices foram contemporâneas das Escolas Normais e dos Grupos Escolares, e se diferenciaram quando investiram numa formação socioeducativa de assistência ao menor "desvalido" ou "transviado", pela aprendizagem de um ofício e preparação para o trabalho.

Com este intento, em 23 de setembro de 1909, pelo Decreto no 7566, o Presidente da República dos Estados Unidos do Brasil, Nilo Peçanha, criou nas capitais dos Estados da República Escolas de Aprendizes Artífices para o ensino profissional primário gratuito.

O decreto de criação das Escolas de Aprendizes Artífices considerou que o aumento constante da população das cidades exigia que se facilitasse às classes proletárias os meios de vencer as dificuldades concernentes à luta pela sobrevivência.

Para isso se tornava necessário, conforme justificativa apresentada no decreto, não só habilitar "os filhos dos desfavorecidos da fortuna" com o indispensável preparo técnico e intelectual, mas também fazê-los adquirir hábitos de trabalho profícuo que os afastasse da ociosidade ignorante, escola do vício e do crime. O decreto, ainda estabelecia a criação das Escolas de Aprendizes Artífices como um dever do Governo da República no intuito de formar cidadãos úteis a Nação. (BRASIL, 1909).

\section{A ESCOLA DE APRENDIZES ARTÍFICES DE NATAL}

Foi, a partir do Decreto no 7566/1909, que a Escola de Aprendizes Artífices foi instalada em Natal (RN), no antigo edifício do Hospital da Caridade Jovino Barreto, situado à rua Presidente Passos no bairro Cidade Alta. (RIO GRANDE DO NORTE, 1909).

A Escola de Aprendizes Artífices de Natal, inaugurada em 3 de janeiro de 1910, de acordo com o decreto de criação, cabia:

[...] formar operários e contra-mestres, ministrando-se o ensino prático e os conhecimentos technicos necessários aos menores que pretenderem aprender um officio, havendo para isso ate o numero de cinco officinas de trabalho manual ou mecânico que forem mais convenientes e necessárias no Estado em que funccionar a escola, consultadas quando possível, as especialidades das industrias locaes. (BRASIL, 1909). 
Com esse intuito de formar operários e contra-mestres, a Escola de Aprendizes Artífices de Natal começou suas atividades oferecendo dois cursos noturnos: primário, obrigatório para que não soubessem ler, escrever e contar, e outro de desenho, também obrigatório, para os alunos que necessitassem dessa disciplina para o exercício satisfatório do ofício que aprendiam. Havia também as oficinas de trabalho manual ou mecânico que funcionavam durante o dia. Eram as oficinas de sapataria, de marcenaria, de alfaiataria, de serralheria e de funilaria.

Para a oferta do ensino profissional primário gratuito, a Escola de Aprendizes Artífices de Natal contava com uma equipe formada por um diretor, um escriturário, mestres de oficinas e um porteiro contínuo. Sendo admitidos meninos com idades entre 10 e 13 anos e que "[...] não sofressem de moléstia infecto-contagiosa, nem [...] [tivessem] defeitos que o impossibilitem para o aprendizado do offício." (BRASIL, 1909).

Os meninos admitidos na escola escolhiam uma das oficinas para obterem formação profissional. Os artefatos produzidos nas oficinas poderiam ser vendidos, mas parte deles eram anualmente expostos com o objetivo de "[...] julgamento do grau de adiantamento dos alunos e distribuição dos prêmios aos mesmos." (BRASIL, 1909).

De acordo com a observância do Decreto de no 7566, de 23 de setembro de 1909, no dia 11 de abril de 1912 ocorreu uma premiação que considerava o grau de adiantamento dos estudantes. A solenidade de premiação foi no salão nobre do Natal Clube. O primeiro prêmio recebeu o nome Rio Branco, o segundo o nome Pedro de Toledo e o terceiro o nome Alberto Maranhão. O aprendiz de marceneiro Inocêncio Manoel do Nascimento recebeu o primeiro prêmio; o aprendiz de alfaiate Salvador Carneiro recebeu o segundo prêmio. O terceiro prêmio que homenageava o Governador do Estado foi recebido pelo aprendiz de sapateiro Elói Marques do Nascimento. (ESCOLA, 1912).

Nessa cerimônia de premiação os aprendizes entoaram o Hino Nacional e o Hino do Trabalho na presença de autoridades como Manoel Dantas que representava o Ministério da Agricultura, Industria e Comércio, ao qual as Escolas de Aprendizes Artífices estavam vinculadas.

As cerimônias de premiação dos alunos das oficinas, como as ocorridas em 1912, configuravam-se elementos da cultura escolar dessa instituição, destinada a realçar comportamentos louváveis e desempenho exemplar dos aprendizes artífices diante da sociedade natalense. Essa premiação dos alunos das oficinas era um componente da cultura escolar.

Conforme Julia (2001) o conceito de cultura escolar está relacionado às práticas cotidianas, aos saberes pedagógicos, às apropriações dos tempos e dos espaços, às táticas dos discentes, ao conjunto de regras a obedecer, saberes a ensinar e condutas a inculcar.

Mas, a escola e sua cultura com o passar dos anos foi também cadenciando o tempo e os outros eventos sociais do meio urbano. Foi o que ocorreu em 1913 quando a exposição escolar dos artefatos produzidos pelos alunos da escola coincidiu com o término das sessões legislativas estaduais.

Nesse mesmo dia, o Governador do Estado, o Senhor Alberto Maranhão, em mensagem apresentada ao Congresso Legislativo na abertura da Primeira Sessão da Oitava Legislatura, cedeu 
ao Governo Federal a escritura pública do prédio da Avenida Rio Branco, no 743, que abrigaria a escola.

Por ocasião, os alunos fardados e desfilando pela cidade, acompanhados pela banda marcial, marcaram também o fim do ano letivo e a mudança das instalações da escola que, temporariamente, se transportou para a antiga sede do Natal Clube. Essa mudança de endereço demonstrava não apenas a demarcação de uma geografia escolar, também significava que a instituição ampliava seu campo de atuação pedagógico, reconfigurando o seu currículo e ressignificando as práticas de formação dos "dos filhos dos outros."

O prédio da Avenida Rio Branco ostenta opulência e estética nos seus traços arquitetônicos simétricos. A construção, atualmente reformada pelo Instituto Federal de Educação, Ciência e Tecnologia do Rio Grande do Norte para funcionar o Memorial da Educação Profissional e o Campi Avançado da Cidade Alta, representa o poder econômico e político-social assumidos pela instituição na cidade do Natal na primeira metade do século XX.

A materialização de um investimento de grande envergadura anunciava que o ensino profissional tornava-se preocupação do Estado, de forma que Ministério da Agricultura, Indústria e Comércio abriu concorrência pública para as primeiras obras no edifício. (EDITAIS, 1914). Previa também que ocorreriam, em décadas posteriores, significativas reformas educacionais na rede nacional de Escolas Industriais.

As modificações dos espaços, segundo Frago e Escolano (2001) criam novos sentidos e configurações aos lugares e territórios. É o que denominam de micropolítica dos espaços, pelos quais as instituições se estabelecem como centros de decisão e poder. A arquitetura passa a ser tratada como "forma de escritura no espaço" responsável por um discurso e parte integrante do currículo escolar.

Apesar do novo endereço e o período das obras de adaptação no prédio da Avenida Rio Branco, as atividades na escola continuaram, até o final da década de 1930, destinadas à formação de aprendizes artífices por um ensino profissional primário e gratuito. Com esse intuito, os alunos passavam a compor a Associação Cooperativa de Mutualidade da Escola de Aprendizes Artífices de Natal que, através das Caixas de Mutualidade objetivavam conter a evasão escolar, facilitar a produção das oficinas e aumentar a renda proveniente da produção nas oficinas. (MEDEIROS, [2012?]).

A renda das oficinas e os subsídios decorrentes do Ministério da Agricultura, Indústria e Comércio possibilitaram aos alunos o recebimento de ferramentas necessárias aos seus ofícios ao terminarem seus cursos.

Dessa maneira, ao término dos cursos os alunos eram diplomados e recebiam ferramentas. Foi o que aconteceu em 7 de julho de 1916 em sessão solene da Assembleia Geral da Associação Cooperativa de Mutualidade da Escola de Aprendizes Artífices de Natal.

Os alunos que estavam sendo diplomados em Alfaiataria receberam uma máquina de costura, uma tesoura, um jogo de ferros de cinco quilos, um fogareiro e uma medida. Já os 
formandos de Serralheria receberam uma forja portátil, uma safra, uma marreta, um martelo, uma escala de aço e dois compassos. (ESCOLA, 1916).

O recebimento dessas ferramentas representava uma formação para o trabalho, no caso específico, de artífices. Mas, o contexto da Primeira Guerra Mundial e as latentes necessidades de industrialização do Brasil requeria das Escolas de Aprendizes Artífices criadas nas capitais federais um redirecionamento dessas práticas de formação.

Nesse contexto, o Ministério da Agricultura, Indústria e Comércio criou, em 1920, a comissão ou serviço de remodelação do ensino técnico profissional. (QUELUZ, 1998). O desafio da comissão era vencer a falta de professores e mestre qualificados, o mal aparelhamento das oficinas e a inadequação dos edifícios para uma produção fabril e a oposição de alguns diretores às mudanças.

Com vistas a sobrepor esses desafios, a comissão de remodelação criou um corpo de inspetores que se revezaram nas direções das Escolas de Aprendizes Artífices do país. Grande parte desses inspetores era da Escola de Engenharia de Porto Alegre que foi apontada como instituição modelo para o ensino técnico no Brasil. (GURGEL, 2007).

A comissão de remodelação orientava acerca da necessidade de aprimorar a formação das elites técnicas e a educação industrial do povo. Para tanto, iniciou a tarefa de tradução e elaboração de livros e manuais técnicos. Foi nesse período que a Escola de Aprendizes Artífices de Natal recebeu livros indicados por essa comissão. Os livros como Desenho Figurativo, Curso de desenho, Modelagem e Modelação, Empalhação e Estofaria de Cartonagens, Manuais de Artefatos de Madeira, Manual de Desenho de Máquinas, Curso de Exercícios Profissionais e de Iniciação aos Trabalhos Manuais e de Desenho.

Outras ações para a remodelação do ensino técnico no Brasil foram balizadas pelo Relatório Lüderitz que defendia a aplicação de um Plano Nacional de Ensino nas escolas de aprendizes artífices, pois era apontada a necessidade de transpor as limitações da tradição artesanal pelo domínio da máquina e do trabalho industrial. (NAGLE, 1974).

As ideias e indicações do Relatório Lüderitz inspiraram a Consolidação dos Dispositivos Concernentes às Escolas de Aprendizes Artífices, aprovada em 1926 pelo Ministério de Agricultura, Industria e Comercio que estabelecia o aumento da duração dos cursos de quatro para seis anos e o desdobramento de cada oficina em seções de ofícios correlatos.

Com isso a Escola de Aprendizes Artífices de Natal passou a ofertar do 1으 ao 40 ano os cursos primário e de desenho, cuja estrutura curricular era composta por:

10 ano: leitura e escrita, caligrafia, contas, lição de coisas42, desenho e trabalhos manuais, ginástica e canto.

20 ano: leitura e escrita, caligrafia, contas, lição de coisas, desenho e trabalhos manuais, ginástica e canto, elementos de geometria, geografia e história pátria, instrução moral e cívica. 
3o ano: português, aritmética, geometria, geografia e história pátria, instrução moral e cívica, lição de coisas, caligrafia, desenho ornamental e de escala, aprendizagem nas oficinas.

40 ano: português, aritmética, geometria, rudimentos de física, instrução moral e cívica, desenho ornamental e de escala, desenho industrial e tecnologia, aprendizagem nas oficinas. (MEDEIROS, [2012?]).

A aprendizagem de trabalhos manuais como etapa pré-vocacional à prática do ofício propriamente dito seria adquirida durante o 30 e 40 anos. $\mathrm{O}$ aluno ainda podia permanecer na instituição por mais dois anos complementares.

A partir das deliberações da Consolidação dos Dispositivos Concernentes às Escolas de Aprendizes Artífices foram criadas as seguintes seções de trabalhos para substituir as oficinas: Seção de Trabalhos de Madeira, Seção de Trabalhos de Metal, Seção de Fabrico de Calçados, Seção de Feitura do Vestuário. Anos mais tarde também foram instaladas a Seção de Artes Decorativas e a Seção de Artes do Couro.

Em 1930, as escolas profissionais passaram a jurisprudência do Ministério dos Negócios da Educação e da Saúde Pública, criado pelo Decreto no 19402, de 14 de novembro de 1930. Ligado a esse Ministério ficou a comissão de remodelação do ensino técnico que promoveu reformulações nas Escolas de Aprendizes Artífices. Essa comissão foi extinta e, em 1931, foi criada a Inspetoria de Ensino Profissional Técnico com a competência de dirigir, orientar e fiscalizar o ensino profissional técnico. (BRASIL, 1931).

O Ministério de Educação e Saúde sob o comando de Gustavo Capanema deu nova estruturação a educação profissional com a criação da Divisão do Ensino Industrial. Nesse contexto de reforma educacional, as Escolas de Aprendizes Artífices passaram à denominação de Liceus Industriais. Assim, em 1937 a Escola de Aprendizes Artífices de Natal passou a denominarse Liceu Industrial de Natal. (BRASIL, 1937).

\section{DE EAA PARA LICEU INDUSTRIAL DE NATAL}

No ano em que a escola passou a chamar-se Liceu Industrial de Natal foi inaugurado novos pavilhões localizados na ala esquerda do edifício principal, na Avenida Rio Branco, onde foram construídos uma cozinha, um refeitório e sanitários. Na inauguração compareceram o Governador do Estado, Rafael Fernandes, o Secretário Geral do Estado, Aldo Fernandes, o Cônego Amâncio Ramalho, o diretor do Departamento de Educação, Paulo Viveiros, discentes e docentes da escola.

O Liceu Industrial de Natal passou a ocupar uma área mais ampla na qual se instalavam não só as sessões de trabalho, mas também espaços como a Sala das Armas na qual era disposta o instrumental da Banda de Tiro do Liceu e as suas armas de instrução. A Banda de Tiro era vinculada a Escola de Instrução Militar 271, pertencente ao comando da 7ạ Região Militar do Exército Nacional que funcionava na escola antes mesmo da lei de Ensino Militar de 23 de dezembro de 1937. (BRASIL, 1938). 
As instalações da Escola Industrial de Natal constitui patrimônio histórico da cultura material, elemento importante para compreender a história da educação profissional brasileira. Espaços físicos semelhantes, quando preservados, possibilitam o cultivo da memória viva de um período histórico, de forma que esses lugares assumem a função de documento-testemunho. (LE GOFF, 1996).

O cultivo do civismo e do militarismo no interior das instituições de ensino dessa natureza revela a preocupação com o disciplinamento dos corpos como parte integrante e essencial na (com)formação dos sujeitos. O patriotismo era sentimento e prática presente no cotidiano escolar, de forma que extrapolava as fronteiras do currículo oficial, de tal forma que, segundo Silva (2012), egressos da escola seguiram carreira militar. O cultivo da moralização e o respeito aos símbolos que representavam o país eram incorporados e materializados em projetos de vida.

Além da Escola de Instrução Militar 271, o Liceu Industrial de Natal incorporava em sua cultura escolar eventos educacionais como a Semana da Criança, com o Grupo de Escoteiros Artífices, instalado no dia 13 de outubro de 1939, e com o Centro Lítero-Recreativo Nilo Peçanha, criado em 15 de janeiro de 1940.

Nilo Peçanha, o Presidente da República que instituiu o ensino profissional primário e gratuito, dava nome ao Centro Lítero-Recreativo e, em 1942, foi novamente homenageado, pois a biblioteca da escola, mantida pelo referido centro, também recebeu a mesma denominação.

A cultura escolar do Liceu Industrial de Natal foi marcada pela prática esportiva. Para a quadra de esportes do Liceu concorriam clubes de voleibol e basquetebol de Natal. Os torneios mobilizavam não somente os alunos, mas a comunidade escolar que afluía para torcer pelos times e prestigiar o evento de cunho socioeducativo. Essa efervescência de atividade na escola estimulava a socialização e a aproximação escola-aluno.

Escola de Aprendizes Artífices e Liceu Industrial de Natal foram as denominações recebidas pela escola destinada a educação profissional no Rio Grande do Norte. E, no ano de 1942, com a promulgação da Lei Orgânica do Ensino Industrial a organização do ensino profissional foi profundamente alterada.

Essa lei estabeleceu as bases de organização e de regime do ensino industrial, de grau secundário, destinado à preparação profissional dos trabalhadores da indústria e das atividades artesanais, e ainda dos trabalhadores dos transportes, das comunicações e da pesca.

A Lei Orgânica do Ensino Industrial tinha por finalidade formar profissionais aptos ao exercício de ofícios e técnicas nas atividades industriais; dar aos trabalhadores jovens e adultos da indústria, não diplomados, uma qualificação profissional; aperfeiçoar ou especializar os conhecimentos e capacidades de trabalhadores diplomados ou habilitados a divulgar conhecimentos de atualidades técnicas.

Os cursos industriais passavam a receber alunos com a formação primária completa para cursarem os cursos industriais de duração de quatro anos. Com isso, não só a dinâmica formativa da escola foi alterada, mas também sua denominação que deixava de ser Liceu Industrial de Natal para tornar-se Escola Industrial de Natal. 


\section{ALGUMAS CONSIDERAÇÕES}

As Escolas de Aprendizes Artífices inauguraram a política de educação profissional no Brasil e tornaram-se palco dos anseios de uma educação para o trabalho. A EAA de Natal mantinha um currículo e um conjunto de práticas voltado à formação do profissional autônomo como o sapateiro, o marceneiro e o curtidor.

As práticas das oficinas estavam mais próximas do modelo de produção manufatureiro do que ao industrial, introdutor da mecânica de máquinas pesadas. Mas, a cultura escolar da EAA de Natal também estava (de)marcada por atividades cívico-patrióticas, socioculturais que visavam uma formação para o trabalho e uma formação moral.

Durante os anos 1910-30, a presença de uma instituição que visava assistir os "desafortunados" foi capaz de fundamentar um tipo de cultura escolar promotora de dinamicidade histórica, gestora de outras fases e faces que integram a história da educação profissional no Rio Grande do Norte.

\section{REFERÊNCIAS BIBLIOGRÁFICAS:}

1. BRASIL. Decreto n. 019.560 de 5 de janeiro de 1931. Aprova o regulamento que organiza a Secretaria de Estado do Ministério da Educação e da Saúde Pública. Rio de Janeiro: Imprensa Nacional, 31 dez. 1931. Coleção de Leis do Brasil. Disponível em: <http://www6.senado.gov.br>. Acesso em: 10 jan. 2012.

2. BRASIL. Decreto no. 7.566 de 23 de setembro de 1909. Cria nas Capitais dos Estados da República Escolas de Aprendizes Artífices para o ensino profissional primário e gratuito. Coleções de Leis do Brasil. Imprensa Nacional: Rio de Janeiro, 31 dez. 1909. Disponível em: <http://www6.senado.gov.br>. Acesso em: 10 jan. 2012.

3. BRASIL. Decreto no. 9.070 de 25 de outubro de 1911. Dá novo regulamento às escolas de aprendizes artífices. Coleções de Leis do Brasil. Imprensa Nacional: Rio de Janeiro, 31 dez. 1911. Disponível em: <http://www6.senado.gov.br>. Acesso em: 10 jan. 2012.

4. BRASIL. Decreto-lei no. 432 de 19 de maio de 1938. Regula o ensino militar no Exército. Rio de Janeiro: Imprensa Nacional, 31 dez. 1938. Coleção de Leis do Brasil. Disponível em: <http://www6.senado.gov.br>. Acesso em: 4 jun. 2011.

5. BRASIL. Lei no. 378 de 13 de janeiro de 1937. Dá nova organização ao Ministério da Educação e Saúde Pública. Rio de Janeiro: Diário Oficial da União, 15 jan. 1937. p.1210, coluna 1. Coleção de Leis do Brasil. Disponível em: <http://www6.senado.gov.br>. Acesso em: Acesso em: 10 jan. 2012. 
6. EDITAIS. Concorrência para as obras de adaptação do prédio destinado à Escola de Aprendizes Artífices neste Estado. A República, Natal, p. 2, 3 ago. 1914.

7. ESCOLA de Aprendizes Artífices. A República, Natal, 22 abr. 1912.

8. ESCOLA de Aprendizes Artífices. A República, Natal, 7 jul. 1916.

9. FRAGO, Antonio Viñao; ESCOLANO, Augustin. Arquitetura como programa. Espaço-escola e currículo. Currículo, espaço e subjetividade: a arquitetura como programa. 2. Ed. Rio de Janeiro: DP\&A, 2001.

10. GURGEL, Rita Diana de Freitas. A trajetória da Escola de Aprendizes Artífices de Natal: República, Trabalho e Educação (1909-1942). 2007, 232f. Tese (Doutorado em Educação). Universidade Federal do Rio Grande do Norte, Natal, 2007.

11. JULIA, Dominique. A cultura escolar como objeto histórico. Revista Brasileira de História da Educação, Campinas, n. 1, p. 9-43, jan/jun.2001.

12. LE GOFF, Jacques. História e Memória. 4. ed. Campinas, SP: Editora da UNICAMP, 1996.

13. SILVA, Maria Da Guia de Sousa. Escola Industrial de Natal e a Formação de Jovens para o Exercício de uma Profissão (1942-1968). 2012, 232 f. Tese (Doutorado em Educação)Universidade Federal do Rio Grande do Norte, Natal, 2012.

14. MEDEIROS, Arilene Lucena de. A forja e a pena: técnica e humanismo na trajetória da Escola de Aprendizes Artífices de Natal até a Escola Técnica Federal do Rio Grande do Norte. Natal: Editora do IFRN, [2012?].

15. NAGLE, Jorge. Educação e sociedade na Primeira República. São Paulo: EPU, 1974.

16. QUELUZ, Gilson Leandro. Método intuitivo e o Serviço de Remodelação do Ensino Técnico Profissional. Revista Educação e Tecnologia, v. 3, n.2, São Paulo, 1998. Disponível em: $<$ http://revistas.utfpr.edu.br/pb/index.php/revedutec-ct/article/view/1036>. Acesso em: 10 jan. 2012.

17. RIO GRANDE DO NORTE (Estado). Presidente Alberto Maranhão. Mensagem apresentada ao Congresso Legislativo na abertura da Terceira Sessão da Sexta Legislatura em 1 de novembro de 1909. Natal: Typografia d’A República, 1909, p. 9. 